\title{
Cytoreductive Nephrectomy in Patients with Synchronous Metastases from Renal Cell Carcinoma: Results from the International Metastatic Renal Cell Carcinoma Database Consortium
}

\author{
Daniel Y.C. Heng ${ }^{a, * \dagger}$, J. Connor Wells ${ }^{a, \dagger}$, Brian I. Rini ${ }^{b}$, Benoit Beuselinck ${ }^{c}$, Jae-Lyun Lee $^{d}$, \\ Jennifer J. Knox ${ }^{e}$, Georg A. Bjarnason ${ }^{f}$, Sumanta Kumar Pal ${ }^{g}$, Christian K. Kollmannsberger ${ }^{h}$, \\ Takeshi Yuasa ${ }^{i}$, Sandy Srinivas ${ }^{j}$, Frede Donskov ${ }^{k}$, Aristotelis Bamias $^{l}$, Lori A. Wood ${ }^{m}$, \\ D. Scott Ernst ${ }^{n}$, Neeraj Agarwal ${ }^{o}$, Ulka N. Vaishampayan ${ }^{p}$, Sun Young Rha ${ }^{q}$, Jenny J. Kim ${ }^{r}$, \\ Toni K. Choueiri ${ }^{s}$ \\ ${ }^{\mathrm{a}}$ Tom Baker Cancer Center, Calgary, Alberta, Canada; ${ }^{\mathrm{b}}$ Cleveland Clinic Taussig Cancer Institute, Cleveland, OH, USA; ${ }^{\mathrm{c}}$ University Hospitals Leuven, Leuven, \\ Belgium; ${ }^{\mathrm{d}}$ Asan Medical Center, Seoul, South Korea; ${ }^{\mathrm{e}}$ Princess Margaret Cancer Centre, Toronto, Ontario, Canada; ${ }^{\mathrm{f}}$ Sunnybrook Odette Cancer Centre, \\ Toronto, Ontario, Canada; ${ }^{\mathrm{g}}$ City of Hope Comprehensive Cancer Cente, Duarte, CA, USA; ${ }^{\mathrm{h}}$ BCCA Vancouver Cancer Centre, Vancouver, British Columbia, \\ Canada; ${ }^{\mathrm{i}}$ Cancer Institute Hospital of Japanese Foundation for Cancer Research, Tokyo, Japan; ${ }^{\mathrm{j}}$ Stanford Medical Center, Stanford, CA, USA; ${ }^{\mathrm{k}}$ Aarhus \\ University Hospital, Aarhus, Denmark; ${ }^{1}$ Department of Clinical Therapeutics, National \& Kapodistrian University, Athens, Greece; ${ }^{\mathrm{m}}$ Queen Elizabeth II Health \\ Sciences Centre, Halifax, Nova Scotia, Canada; ${ }^{\mathrm{n}}$ London Regional Cancer Centre, London, Ontario, Canada; ${ }^{\circ}$ University of Utah Huntsman Cancer Institute, \\ Salt Lake City, UT, USA; ${ }^{\mathrm{p}}$ Karmanos Cancer Institute, Detroit, MI, USA; ${ }^{\mathrm{q}}$ Yonsei University College of Medicine, Seoul, South Korea; ${ }^{\mathrm{r}}$ Sidney Kimmel \\ Comprehensive Cancer Center at John Hopkins University, Baltimore, MD, USA; ${ }^{\mathrm{s}}$ Dana-Farber Cancer Institute, Boston, MA, USA
}

\section{Article info}

Article history:

Accepted May 26, 2014

Keywords:

Cytoreductive nephrectomy Metastatic renal cell carcinoma Targeted therapy

\begin{abstract}
Background: The benefit of cytoreductive nephrectomy (CN) for overall survival (OS) is unclear in patients with synchronous metastatic renal cell carcinoma (mRCC) in the era of targeted therapy.

Objective: To determine $\mathrm{OS}$ benefit of $\mathrm{CN}$ compared with no $\mathrm{CN}$ in mRCC patients treated with targeted therapies.

Design, setting, and participants: Retrospective data from patients with synchronous mRCC $(n=1658)$ from the International Metastatic Renal Cell Carcinoma Database Consortium (IMDC) were used to compare $982 \mathrm{mRCC}$ patients who had a CN with 676 mRCC patients who did not.

Outcome measurements and statistical analysis: OS was compared and hazard ratios (HRs) adjusted for IMDC poor prognostic criteria.

Results and limitations: Patients who had $\mathrm{CN}$ had better IMDC prognostic profiles versus those without (favorable, intermediate, or poor in $9 \%, 63 \%$, and $28 \%$ vs $1 \%, 45 \%$, and $54 \%$, respectively). The median OS of patients with $\mathrm{CN}$ versus without $\mathrm{CN}$ was 20.6 versus $9.5 \mathrm{mo}(p<0.0001)$. When adjusted for IMDC criteria to correct for imbalances, the HR of death was 0.60 (95\% confidence interval, $0.52-0.69 ; p<0.0001$ ). Patients estimated to survive $<12$ mo may receive marginal benefit from CN. Patients who have four or more of the IMDC prognostic criteria did not benefit from CN. Data were collected retrospectively.

$\dagger$ Contributed equally as first author.

* Corresponding author. University of Calgary, Tom Baker Cancer Center, 1331 29th Street NW, Calgary, AB, T2N 4N2 Canada. Tel. +1 403521 3166; Fax: +403 2831651.

E-mail address: daniel.heng@albertahealthservices.ca (Daniel Y.C. Heng).
\end{abstract}


Conclusions: $\mathrm{CN}$ is beneficial in synchronous mRCC patients treated with targeted therapy, even after adjusting for prognostic factors. Patients with estimated survival times $<12 \mathrm{mo}$ or four or more IMDC prognostic factors may not benefit from $\mathrm{CN}$. This information may aid in patient selection as we await results from randomized controlled trials.

Patient summary: We looked at the survival outcomes of metastatic renal cell carcinoma patients who did or did not have the primary tumor removed. We found that most patients benefited from tumor removal, except for those with four or more IMDC risk factors.

(C) 2014 Published by Elsevier B.V. on behalf of European Association of Urology.

\section{Introduction}

Over the past decade, our molecular understanding of metastatic renal cell carcinoma ( $\mathrm{mRCC}$ ) has vastly improved. Since 2005, targeted therapies have been designed to target pathways involved in RCC pathogenesis, leading to the approval of the vascular endothelial growth factor (VEGF) inhibitors sunitinib, sorafenib, pazopanib, bevacizumab, and axitinib, and the mammalian target of rapamycin (mTOR) inhibitors temsirolimus and everolimus. Targeted therapies have demonstrated impressive gains in overall survival (OS), progression-free survival (PFS), and response rates over the previously utilized immunotherapies [1-3].

In the era of immunotherapy (1992-2004), a combined analysis of two prospective randomized clinical trials from the European Organization for Research and Treatment of Cancer (EORTC) and SWOG demonstrated that cytoreductive nephrectomy $(\mathrm{CN})$ followed by interferon- $\alpha$ treatment had a 5.8-mo increased OS versus immunotherapy alone (13.6 vs $7.8 \mathrm{mo}$ ) [4-6]. The results solidified the role of $\mathrm{CN}$ in the immunotherapy era of mRCC treatment. However, with more effective targeted therapies largely supplanting immunotherapy, it is not well understood if $\mathrm{CN}$ should remain a part of the standard treatment protocol. The rates of $\mathrm{CN}$ have declined since the introduction of targeted therapy $[7,8]$. This large retrospective international study was performed to address the survival benefit of $\mathrm{CN}$ in mRCC patients treated with targeted therapy.

\section{Methods}

\subsection{Patient population}

Patient data were collected from 20 international cancer centers from Canada, the United States, Belgium, South Korea, Japan, Denmark, Greece, and Singapore. Patient inclusion criteria were composed of mRCC diagnosis of any type and treatment with a VEGF or mTOR targeted therapy (sunitinib, sorafenib, axitinib, bevacizumab, temsirolimus, pazopanib, or everolimus).

Data were collected using uniform database software and templates. Demographic, clinical, and laboratory data include those found to have prognostic value [9-11] (Table 1). Laboratory values were standardized against their respective institution upper limit of normal (ULN) and lower limit of normal (LLN) values as necessary. Measured outcomes included OS and PFS. This study received institutional review board approval from each participating center.

\subsection{Statistical analysis}

The primary outcome was OS from the initiation of first-line targeted therapy to the date of death or censored at last follow-up. PFS was defined as the initiation of targeted therapy to the date of progression, drug cessation, or censored at last follow-up. Median OS and PFS distributions were estimated using the Kaplan-Meier method.

Cox proportional hazards regression was used to determine hazard ratios (HRs) for OS after adjustment for known International Metastatic Renal Cell Carcinoma Database Consortium (IMDC) prognostic factors: hemoglobin below LLN, corrected calcium greater than ULN, neutrophils above ULN, platelets greater than ULN, Karnofsky performance status $<80 \%$, and time from diagnosis to treatment $<1 \mathrm{yr}$ [11]. Adjusted HRs and $p$ values were reported. Subgroup analysis and HRs were determined for IMDC favorable-, intermediate-, and poor-risk groups as well as other covariates of interest.

Incremental survival benefits were compared between those who received a $\mathrm{CN}$ versus those who did not in patients who survived $<3,6,9$, 12,18 , and $24 \mathrm{mo}$. An exploratory subgroup analysis of patients with $0-6$ of the IMDC prognostic factors was performed to determine any differences in OS. Statistical analyses were performed with SAS v.9.2, defining $p<0.05$ (two sided) as statistically significant.

\section{Results}

\subsection{Patient characteristics and outcomes}

A total of 2569 of 3245 IMDC mRCC patients (79\%) received a nephrectomy. Patients who had a nephrectomy before the diagnosis of metastatic disease (ie, those with metachronous metastases) were excluded ( $n=1587)$. Among remaining patients ( $n=1658$ ), 982 underwent a CN; 676 did not. These were the final numbers for analysis. The median follow-up of all patients was 39.1 mo (95\% confidence interval [CI], 36.0-41.5). At the time of analysis, 1137 patients (68.6\%) had died, and 1416 (85.4\%) had experienced disease progression.

All patients received targeted therapy, with most receiving first-line sunitinib (72\%). Table 1 shows the comparison of baseline characteristics between $\mathrm{CN}$ and non-CN patients. Patients receiving a $\mathrm{CN}$ had better IMDC prognostic profiles: 9\% favorable, 63\% intermediate, and $28 \%$ poor compared with the non-CN profiles, $1 \%$ favorable, $45 \%$ intermediate, and $54 \%$ poor $(p<0.001)$. Fewer $\mathrm{CN}$ patients had non-clear cell pathology $(p=0.042)$, bone metastases $(p=0.001)$, and liver metastases $(p=0.001)$, but $\mathrm{CN}$ patients had more sarcomatoid features $(<0.001)$.

\subsection{Univariable and multivariable analysis}

The median OS for CN patients was 20.6 versus 9.6 mo for patients not receiving a $\mathrm{CN}$ (Fig. 1; $p<0.001$ ). After adjustment with IMDC risk factors that were different between the two populations, a clear OS benefit was 
Table 1 - Patient characteristics at initiation of targeted therapy by nephrectomy status

\begin{tabular}{|c|c|c|c|}
\hline Baseline characteristics & No CN $(n=676), n / n(\%)$ & $\mathrm{CN}(n=982), n / n(\%)$ & $p$ value \\
\hline Age, $\mathrm{yr}^{*}$ & $59.9(54.6-70.0)$ & $59.3(52.7-67.4)$ & 0.740 \\
\hline \multicolumn{4}{|l|}{ Gender } \\
\hline Male & $488 / 676(72)$ & $721 / 982(73)$ & 0.579 \\
\hline Female & $188 / 676(28)$ & $261 / 982(27)$ & \\
\hline \multicolumn{4}{|l|}{ IMDC prognostic criteria } \\
\hline Favorable & $5 / 482(1)$ & $65 / 686(9)$ & $<0.001$ \\
\hline Intermediate & $215 / 482(45)$ & $431 / 686(63)$ & \\
\hline Poor & $261 / 482(54)$ & $190 / 686(28)$ & \\
\hline KPS $<80$ & $233 / 558(42)$ & $158 / 837(19)$ & $<0.001$ \\
\hline Diagnosis to targeted therapy $<1 \mathrm{yr}$ & $639 / 674(95)$ & $695 / 980(71)$ & $<0.001$ \\
\hline Serum corrected calcium $>$ ULN & $120 / 601(20)$ & $76 / 867(8.8)$ & $<0.001$ \\
\hline Hemoglobin $<$ LLN & $446 / 643(69)$ & $570 / 907(63)$ & $<0.008$ \\
\hline Neutrophils $>$ ULN & $166 / 624(27)$ & $127 / 881(14)$ & $<0.001$ \\
\hline Platelets $>$ ULN & $167 / 595(28)$ & $164 / 803(20)$ & 0.001 \\
\hline \multicolumn{4}{|l|}{ Type of targeted therapy } \\
\hline Sunitinib & $533 / 675(79)$ & $654 / 972(67)$ & $<0.001$ \\
\hline Sorafenib & $58 / 675(8.6)$ & $194 / 972(20)$ & \\
\hline Axitinib & $3 / 675(0.4)$ & $4 / 972(0.4)$ & \\
\hline Bevacizumab & $10 / 675(1.5)$ & $42 / 972(4.0)$ & \\
\hline Temsirolimus & $43 / 675(6.4)$ & $35 / 972(3.6)$ & \\
\hline Pazopanib & $19 / 675(2.8)$ & $27 / 972(2.8)$ & \\
\hline Everolimus & $9 / 675(1.0)$ & $9 / 972(1.0)$ & \\
\hline Other & $2 / 675(0.3)$ & $7 / 972(0.7)$ & \\
\hline Non-clear cell pathology & $83 / 533(16)$ & $113 / 954(12)$ & 0.042 \\
\hline Sarcomatoid features & $38 / 442(8.6)$ & $151 / 936(16)$ & $<0.001$ \\
\hline Bone metastases & $305 / 638(48)$ & $359 / 908(40)$ & 0.001 \\
\hline Liver metastases & $153 / 614(25)$ & $151 / 844(18)$ & 0.001 \\
\hline Brain metastases & $64 / 608(11)$ & $72 / 903(8)$ & 0.089 \\
\hline
\end{tabular}

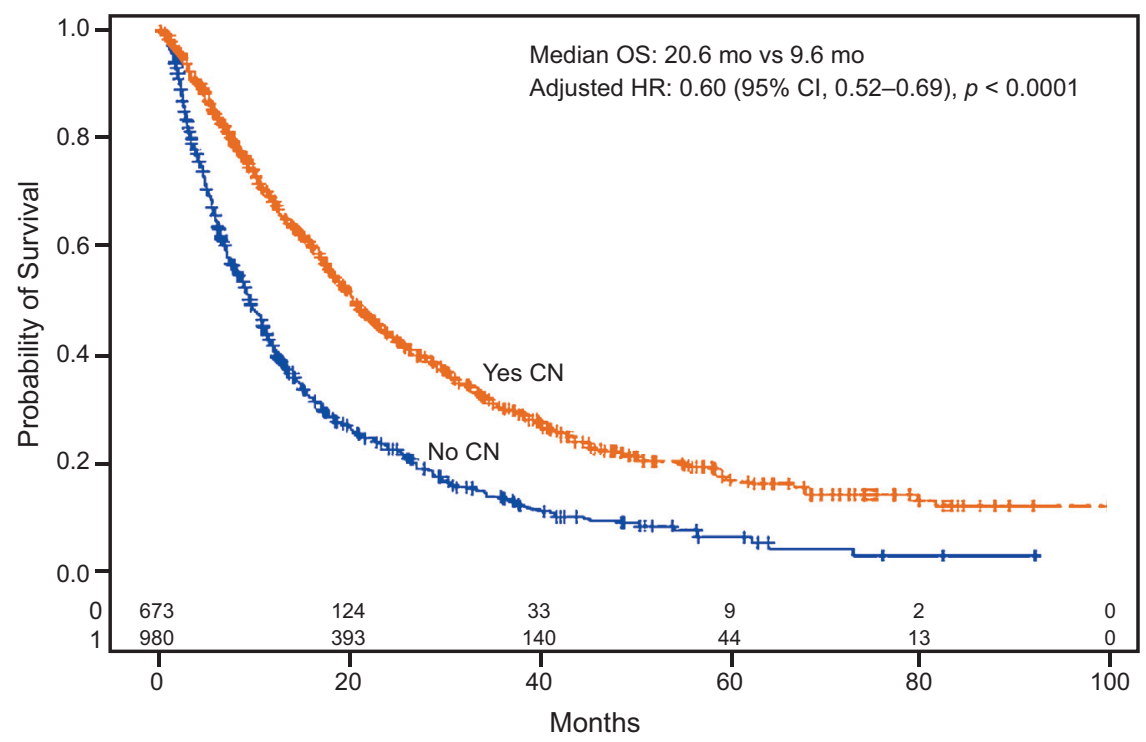

Fig. 1 - Kaplan-Meier curve depicting the overall survival from the initiation of targeted therapy for 1633 metastatic renal cell carcinoma patients who did or did not receive a cytoreductive nephrectomy.

$\mathrm{CI}$ = confidence interval; $\mathrm{CN}$ = cytoreductive nephrectomy; $\mathrm{HR}=$ hazard ratio; $\mathrm{OS}=$ overall survival.

observed in $\mathrm{CN}$ patients (HR: 0.60; 95\% CI, 0.52-0.69; $p<0.001)$. CN was also associated with an increase in PFS: $7.6 \mathrm{mo}(95 \% \mathrm{CI}, 6.7-8.1 ; p<0.001)$ versus $4.5 \mathrm{mo}(95 \% \mathrm{CI}$, 3.9-5.1; $p<0.001)$. PFS adjustment for prognostic factors continued to show a benefit for CN (HR: 0.75; 95\% CI, 0.66$0.85 ; p<0.001)$. Table 2 shows the subgroup analysis of patients receiving $\mathrm{CN}$ compared with those not receiving CN. 
Table 2 - Subgroup analysis of patients receiving and not receiving cytoreductive nephrectomy

\begin{tabular}{|c|c|c|c|c|}
\hline \multirow[t]{2}{*}{ Subgroup analysis } & \multicolumn{2}{|c|}{ Median OS, mo } & \multirow[t]{2}{*}{ Hazard ratio $(95 \% \mathrm{CI})$} & \multirow[t]{2}{*}{$p$ value } \\
\hline & Without CN & With CN & & \\
\hline \multicolumn{5}{|l|}{ Risk } \\
\hline Favorable" & 41.0 & 37.0 & - & - \\
\hline Intermediate & 13.3 & 23.0 & $0.58(0.47-0.71)$ & $<0.001$ \\
\hline Poor & 6.0 & 9.5 & $0.64(0.52-0.78)$ & $<0.001$ \\
\hline \multicolumn{5}{|l|}{ KPS } \\
\hline$>80$ & 12.2 & 23.4 & $0.53(0.45-0.62)$ & $<0.001$ \\
\hline$<80$ & 5.3 & 8.6 & $0.70(0.56-0.88)$ & 0.002 \\
\hline \multicolumn{5}{|l|}{ Age at TKI, yr } \\
\hline$<75$ & 9.6 & 20.8 & $0.52(0.46-0.59)$ & $<0.001$ \\
\hline$>75$ & 8.6 & 16.7 & $0.66(0.44-0.98)$ & 0.038 \\
\hline \multicolumn{5}{|l|}{ No. of metastases } \\
\hline 1 & 15.0 & 38.6 & $0.50(0.38-0.66)$ & $<0.001$ \\
\hline$>1$ & 8.9 & 17.7 & $0.55(0.48-0.63)$ & $<0.001$ \\
\hline \multicolumn{5}{|l|}{ Brain metastases } \\
\hline No & 9.5 & 21.9 & $0.51(0.45-0.58)$ & $<0.001$ \\
\hline Yes & 6.9 & 12.5 & $0.57(0.39-0.83)$ & 0.003 \\
\hline \multicolumn{5}{|l|}{ Liver metastases } \\
\hline No & 10.7 & 21.5 & $0.53(0.46-0.61)$ & $<0.001$ \\
\hline Yes & 6.6 & 10.6 & $0.65(0.51-0.84)$ & 0.001 \\
\hline \multicolumn{5}{|l|}{ Bone metastases } \\
\hline No & 9.5 & 24.3 & $0.48(0.40-0.56)$ & $<0.001$ \\
\hline Yes & 9.3 & 14.9 & $0.65(0.54-0.77)$ & $<0.001$ \\
\hline \multicolumn{5}{|l|}{ Sarcomatoid } \\
\hline No & 10.9 & 22.3 & $0.51(0.44-0.59)$ & $<0.001$ \\
\hline Yes & 5.5 & 10.2 & $0.56(0.36-0.86)$ & 0.009 \\
\hline \multicolumn{5}{|l|}{ Non-clear cell } \\
\hline No & 10.9 & 21.4 & $0.52(0.45-0.59)$ & $<0.001$ \\
\hline Yes & 8.0 & 15.3 & $0.61(0.43-0.87)$ & 0.006 \\
\hline
\end{tabular}

Table 3 - Incremental overall survival benefit from cytoreductive nephrectomy separated by estimated survival times

\begin{tabular}{|c|c|c|c|c|c|}
\hline OS, mo & No CN OS, mo & $\mathrm{CN}$ OS, mo & Incremental benefit, mo & $p$ value & HR (95\% CI) adjusted for IMDC criteria \\
\hline$<24$ & $\begin{array}{l}7.1 \\
n=456\end{array}$ & $\begin{array}{l}12.3 \\
n=480\end{array}$ & +5.2 & $<0.0001$ & $\begin{array}{l}0.72(0.62-0.85) \\
p<0.001 \\
n=676^{*}\end{array}$ \\
\hline$<18$ & $\begin{array}{l}6.7 \\
n=430\end{array}$ & $\begin{array}{l}10.0 \\
n=395\end{array}$ & +3.3 & $<0.0001$ & $\begin{array}{l}0.85(0.72-1.00) \\
p=0.05 \\
n=602^{*}\end{array}$ \\
\hline$<12$ & $\begin{array}{l}5.5 \\
n=366\end{array}$ & $\begin{array}{l}7.3 \\
n=290\end{array}$ & +2.2 & $<0.0001$ & $\begin{array}{l}0.97(0.81-1.17) \\
p=0.761 \\
n=483^{*}\end{array}$ \\
\hline$<9$ & $\begin{array}{l}4.5 \\
n=303\end{array}$ & $\begin{array}{l}5.5 \\
n=218\end{array}$ & +1.0 & 0.0027 & $\begin{array}{l}0.98(0.79-1.20) \\
p=0.811 \\
n=385^{*}\end{array}$ \\
\hline$<6$ & $\begin{array}{l}3.2 \\
n=230\end{array}$ & $\begin{array}{l}4.0 \\
n=151\end{array}$ & +0.8 & 0.0084 & $\begin{array}{l}1.02(0.80-1.31) \\
p=0.856 \\
n=280^{*}\end{array}$ \\
\hline$<3$ & $\begin{array}{l}2.1 \\
n=118\end{array}$ & $\begin{array}{l}2.2 \\
n=71\end{array}$ & +0.1 & 0.9429 & $\begin{array}{l}1.03(0.72-1.46) \\
p=0.878 \\
n=146^{*}\end{array}$ \\
\hline $\begin{array}{l}\mathrm{CI}=\text { conf } \\
\mathrm{OS}=\text { ove } \\
\text { The } n \mathrm{u} \\
\text { case anal }\end{array}$ & $\begin{array}{l}\text { terval; } \mathrm{CN}=\mathrm{cyt} \\
\text { val. } \\
\text { e adjusted HR d } \\
\text { used. }\end{array}$ & $\begin{array}{l}\text { e nephrectc } \\
\text { atch the sur }\end{array}$ & $\begin{array}{l}\text { = hazard ratio; IMDC = Int } \\
\text { gersus no CN patients in ea }\end{array}$ & $\begin{array}{l}1 \text { Met: } \\
\text { e to } \mathrm{m}\end{array}$ & $\begin{array}{l}\text { al Cell Carcinoma Database Consortium; } \\
\text { on prognostic factors because a complete }\end{array}$ \\
\hline
\end{tabular}

\subsection{Incremental benefit analysis}

Incremental benefit analysis (Table 3) demonstrated that the only patient group not to receive an OS benefit from $\mathrm{CN}$ were those estimated to survive $<3$ mo (2.2 vs 2.1 mo OS:
$+0.1 ; p=0.943)$. Patients estimated to survive $\leq 6$ mo experienced a marginal +0.8 OS increase when a $\mathrm{CN}$ was performed ( $4.0 \mathrm{vs} 3.2 \mathrm{mo}$ OS; $p=0.008$ ). The longer a patient was estimated to survive, the greater the OS benefit of CN. Patients estimated to survive $<24$ mo had an OS benefit of 
Table 4 - Overall survival differences in those with and without cytoreductive nephrectomy by number of International Metastatic Renal Cell Carcinoma Database Consortium criteria met

\begin{tabular}{|c|c|c|c|}
\hline No. of IMDC criteria met & No CN OS, mo $(n)$ & CN OS, mo $(n)$ & $p$ value \\
\hline 0 & \multicolumn{3}{|c|}{$92 \%$ of patients $(65 / 71)$ had $\mathrm{CN}$, insufficient number to compare } \\
\hline 1 & $22.5(n=72)$ & $30.4(n=178)$ & 0.002 \\
\hline 2 & $10.2(n=143)$ & $20.2(n=253)$ & $<0.001$ \\
\hline 3 & $10.0(n=113)$ & $15.9(n=106)$ & $<0.001$ \\
\hline 4 & $5.4(n=103)$ & $6.0(n=67)$ & 0.166 \\
\hline 5 & $3.6(n=36)$ & $2.8(n=14)$ & 0.504 \\
\hline 6 & \multicolumn{3}{|c|}{$25 \%$ of patients $(3 / 12)$ had $C N$, insufficient number to compare } \\
\hline
\end{tabular}

+5.2 mo (12.3 vs 7.1 mo OS; $p<0.001)$. However, upon adjusting for prognostic factors, HRs were not significant for those who lived $<3,6$, and 12 mo. Patients who lived $<18$ mo (HR: $0.85 ; 95 \% \mathrm{CI}, 0.72-1.00 ; p=0.05$ ) and $<24 \mathrm{mo}$ (HR: $0.72 ; 95 \% \mathrm{CI}, 0.62-0.85 ; p<0.001$ ) were more likely to derive benefit.

\subsection{International Metastatic Renal Cell Carcinoma Database Consortium criteria for patient selection}

Patients with no prognostic factors were not analyzed because almost all patients (92\% [65 of 71]) had CN. At the other end of the spectrum, those with all six risk factors represented only 12 patients of whom only 3 (25\%) received a $\mathrm{CN}$. Those with one, two, and three risk factors seemed to derive benefit from $\mathrm{CN}$, whereas those with four, five, and six risk factors did not (Table 4). A test for interaction between the number of IMDC prognostic factors and nephrectomy status was statistically significant $(p=0.0005)$, indicating that the prognostic factors modify the effect of nephrectomy on survival.

\section{Discussion}

The need for $\mathrm{CN}$ in the treatment of mRCC during the era of targeted therapy has been questioned due to the lack of supporting level 1 evidence. VEGF and mTOR inhibitors have demonstrated substantial improvements in tumor shrinkage and survival over previously used immunotherapies; thus there is concern over delaying treatment to perform a CN $[2,12-14]$.

Although nephrectomies are a fairly safe procedure, CNs carry a higher mortality rate, and they are associated with higher morbidity and in-hospital complications that may reduce quality of life during recovery compared with those without $\mathrm{CN}$ [15]. However, $\mathrm{CN}$ is used as an inclusion criterion for some clinical trials or at least included patients with a vast majority having $\mathrm{CN}$; thus determining if $\mathrm{CN}$ is indeed beneficial will have broad implications as to how mRCC treatment and research is managed.

To date, this study is the largest analysis demonstrating that $\mathrm{CN}$ provides an OS benefit in patients treated with targeted therapy while also adjusting for known prognostic factors. Our findings suggest that a large benefit exists in both OS and PFS in patients receiving a $\mathrm{CN}$ compared with those without, even after adjusting for imbalances in prognostic criteria (HR: 0.60; 95\% CI, 0.52-0.69; $p<0.001$ and HR: 0.75 ; 95\% CI, 0.66-0.85; $p<0.001$, respectively). The results are consistent with our previous analysis of a smaller cohort of 314 patients from the IMDC that demonstrated a median OS of 19.8 versus $9.4 \mathrm{mo}(p<0.01)$ and an adjusted HR of 0.68 (95\% CI, 0.46-0.99; $p=0.04$ ); however, there were no analyses to elucidate patient selection criteria [16]. The HR is similar to the EORTC trial performed in the age of immunotherapy (HR: $0.54 ; 95 \% \mathrm{CI}$, $0.31-0.94)$ [5].

A large study examining $\mathrm{CN}$ and survival in both the era of immunotherapy and targeted therapy noted an OS of 19 mo for targeted therapy with $\mathrm{CN}$ versus only 4 mo for targeted therapy alone [7]. Because this was performed with Surveillance Epidemiology and End Results (SEER) data, prognostic factors were unavailable and therefore not adjusted for. The results also showed a steady decrease in CN utilization, which peaked at 39\% in 2004 and has decreased by $0.6 \%$ every year since then [7]. The declining trend of $\mathrm{CN}$ after the introduction of targeted therapy was observed elsewhere [8]. However, both of these studies used SEER data that focuses exclusively on the United States; thus it is difficult to ascertain if this is a global trend.

Careful patient selection is critical in determining if a patient will benefit from a $\mathrm{CN}$ because those with poor survival outcome or who are likely to progress rapidly may receive minimal benefit. In our incremental benefit analysis, $\mathrm{CN}$ provided an increase in OS for patients surviving $<6 \mathrm{mo}$; however, when adjusted for prognostic factors, a significant HR was not observed until the $<18$-mo group. Thus patients expected to survive $<12$ mo may receive marginal benefit from a CN. Patients with four, five, and six IMDC risk factors did not appear to derive benefit.

Strengths of our analysis include the large multicenter series of patients that focuses on patients treated with targeted therapies [17]. Unlike clinical trials, the IMDC does not have inclusion criteria, strengthening its use as a population-based method of analysis. To our knowledge, this study is novel in examining the incremental benefits of $\mathrm{CN}$ and using the IMDC prognostic model factors to aid in patient selection. 
Limitations of our study included that it was retrospective and patients may be prone to selection bias, although the use of consecutive patient series from registry and pharmacy data attempted to mitigate that. Our study is also limited in our ability to adjust for prognostic factors that are unknown or not collected because it is not possible to control for all factors, and we were unable to account for perioperative mortality or surgery-related morbidity. Missing data were handled using a complete case analysis; thus any patient with a missing prognostic factor would be excluded from the adjusted analyses to provide the most conservative estimate. To ensure there was not a systematic bias associated with the patients with missing data, outcomes were compared between these patients and those without missing data, and no differences were noted in OS (data not shown). Finally, some patients may have received their $\mathrm{CN}$ before the initiation of targeted therapy that may bias the OS estimate against those with $\mathrm{CN}$; however, this makes the analysis more robust because it may underestimate the OS benefit.

The Clinical Trial to Assess the Importance of Nephrectomy (CARMENA; NCT00930033) will study patients with good performance status (Eastern Cooperative Oncology Group 0 or 1) and randomly assign them to nephrectomy followed by the targeted therapy sunitinib or sunitinib alone. The Immediate Surgery or Surgery After Sunitinib Malate in Treating Patients with Metastatic Kidney Cancer (SURTIME; NCT01099423) clinical trial investigates the benefit of treating mRCC patients with sunitinib before $\mathrm{CN}$ as well as after, compared with sunitinib only after $\mathrm{CN}$. However, these trials are not anticipated to report for some time, so these retrospective data may guide us until then. Combined, the results of these trials will have a more definitive answer for the role of $\mathrm{CN}$ in $\mathrm{mRCC}$ patients treated with targeted therapy.

\section{Conclusions}

Our findings demonstrate that $\mathrm{CN}$ may provide an $\mathrm{OS}$ benefit in mRCC patients treated with targeted therapy. Patients with limited expected survival or those with four or more IMDC prognostic factors may not receive a substantial benefit compared with those expected to survive longer. Stringent patient selection remains vital as we await results from the randomized controlled trials.

Author contributions: Daniel Y.C. Heng had full access to all the data in the study and takes responsibility for the integrity of the data and the accuracy of the data analysis.

Study concept and design: Heng, Choueiri.

Acquisition of data: Heng, Wells, Rini, Beuselinck, Lee, Knox, Bjarnason, Pal, Kollmannsberger, Yuasa, Srinivas, Donskov, Bamias, Wood, Ernst, Agarwal, Vaishampayan, Rha, Kim, Choueiri.

Analysis and interpretation of data: Heng, Wells, Choueiri.

Drafting of the manuscript: Wells, Heng, Choueiri.

Critical revision of the manuscript for important intellectual content: Heng, Wells, Rini, Beuselinck, Lee, Knox, Bjarnason, Pal, Kollmannsberger, Yuasa, Srinivas, Donskov, Bamias, Wood, Ernst, Agarwal, Vaishampayan, Rha, Kim, Choueiri.
Statistical analysis: Heng.

Obtaining funding: Heng.

Administrative, technical, or material support: Heng.

Supervision: None.

Other (specify): None.

Financial disclosures: Daniel Y.C. Heng certifies that all conflicts of interest, including specific financial interests and relationships and affiliations relevant to the subject matter or materials discussed in the manuscript (eg, employment/affiliation, grants or funding, consultancies, honoraria, stock ownership or options, expert testimony, royalties, or patents filed, received, or pending), are the following: Daniel Y.C. Heng is a consultant for Pfizer, Novartis, and Bayer/Onyx. Brian A. Rini is a consultant for Pfizer, GlaxoSmithKline, Aveo, and Bayer/Onyx. He receives research funding from GlaxoSmithKline and Pfizer. Jennifer J. Knox is a consultant for Aveo and receives research funding from Pfizer. Georg A. Bjarnason is a consultant and receives research funding and honoraria from Pfizer. Christian K. Kollmannsberger is a consultant for Pfizer, Novartis, and GlaxoSmithKline. He receives honoraria and research funding from Pfizer, Novartis, and GlaxoSmithKline. Sandy Srinivas is a consultant for Pfizer, Novartis, and Genentech. Frede Donskov receives research funding from Novartis. Lori A. Wood is a consultant for Pfizer and Novartis; she receives research funding from Pfizer, Novartis, and GlaxoSmithKline. Ulka Vaishampayan receives honoraria and research funding from Pfizer, Novartis, and GlaxoSmithKline. Sun Young Rha is a consultant for Pfizer, Novartis, and GlaxoSmithKline, and receives research funding from Novartis and Bayer Korea. Toni K. Choueiri is a consultant for Aveo, Pfizer, Novartis, GlaxoSmithKline, Genentech, and Bayer/Onyx, and receives research funding from Pfizer.

Funding/Support and role of the sponsor: None.

Acknowledgment statement: We are forever grateful to the individual patient and family donors that have made this study possible.

\section{References}

[1] Coppin C, Porzsolt F, Autenrieth M, Kumpf J, Coldman A, Wilt T. Immunotherapy for advanced renal cell cancer. Cochrane Database Syst Rev 2005:CD001425.

[2] Motzer RJ, Hutson TE, Tomczak P, et al. Sunitinib versus interferon alfa in metastatic renal-cell carcinoma. N Engl J Med 2007;356: 115-24.

[3] Motzer RJ, Hutson TE, Tomczak P, et al. Overall survival and updated results for sunitinib compared with interferon alfa in patients with metastatic renal cell carcinoma. J Clin Oncol 2009;27:3584-90.

[4] Flanigan RC,Salmon SE, Blumenstein BA, et al. Nephrectomy followed by interferon alfa-2b compared with interferon alfa-2b alone for metastatic renal-cell cancer. N Engl J Med 2001;345:1655-9.

[5] Mickisch GH, Garin A, van Poppel H, de Prijck L, Sylvester R, European Organisation for Research and Treatment of Cancer (EORTC) Genitourinary Group. Radical nephrectomy plus interferon-alfa-based immunotherapy compared with interferon alfa alone in metastatic renal-cell carcinoma: a randomised trial. Lancet 2001;358:966-70.

[6] Flanigan RC, Mickisch G, Sylvester R, Tangen C, Van Poppel H, Crawford ED. Cytoreductive nephrectomy in patients with metastatic renal cancer: a combined analysis. J Urol 2004;171:1071-6.

[7] Conti SL, Thomas IC, Hagedorn JC, et al. Utilization of cytoreductive nephrectomy and patient survival in the targeted therapy era. Int J Cancer 2014;134:2245-52.

[8] Tsao CK, Small AC, Kates M, et al. Cytoreductive nephrectomy for metastatic renal cell carcinoma in the era of targeted therapy in the United States: a SEER analysis. World J Urol 2013;31:1535-9.

[9] Mekhail TM, Abou-Jawde RM, Boumerhi G, et al. Validation and extension of the Memorial Sloan-Kettering prognostic factors 
model for survival in patients with previously untreated metastatic renal cell carcinoma. J Clin Oncol 2005;23:832-41.

[10] Choueiri TK, Rini B, Garcia JA, et al. Prognostic factors associated with long-term survival in previously untreated metastatic renal cell carcinoma. Ann Oncol 2007;18:249-55.

[11] Heng DY, Xie W, Regan MM, et al. Prognostic factors for overall survival in patients with metastatic renal cell carcinoma treated with vascular endothelial growth factor-targeted agents: results from a large, multicenter study. J Clin Oncol 2009;27:5794-9.

[12] Abel EJ, Culp SH, Tannir NM, et al. Primary tumor response to targeted agents in patients with metastatic renal cell carcinoma. Eur Urol 2011;59:10-5.

[13] Escudier B, Eisen T, Stadler WM, et al. Sorafenib in advanced clearcell renal-cell carcinoma. N Engl J Med 2007;356:125-34.
[14] Hudes G, Carducci M, Tomczak P, et al. Temsirolimus, interferon alfa, or both for advanced renal-cell carcinoma. N Engl J Med 2007;356: 2271-81.

[15] Abdollah F, Sun M, Thuret R, et al. Mortality and morbidity after cytoreductive nephrectomy for metastatic renal cell carcinoma: a population-based study. Ann Surg Oncol 2011;18:2988-96.

[16] Choueiri TK, Xie W, Kollmannsberger C, et al. The impact of cytoreductive nephrectomy on survival of patients with metastatic renal cell carcinoma receiving vascular endothelial growth factor targeted therapy. J Urol 2011;185:60-6.

[17] Heng DY, Xie W, Regan MM, et al. External validation and comparison with other models of the International Metastatic Renal-Cell Carcinoma Database Consortium prognostic model: a populationbased study. Lancet Oncol 2013;14:141-8.

\section{http://esgurs-espu.uroweb.org}

\section{1st Joint Meeting of ESGURS and ESPU}

\section{EAU Section of Genito-Urinary Reconstructive Surgeons (ESGURS) European Society for Paediatric Urology (ESPU)}

21-22 November 2014, Ghent, Belgium

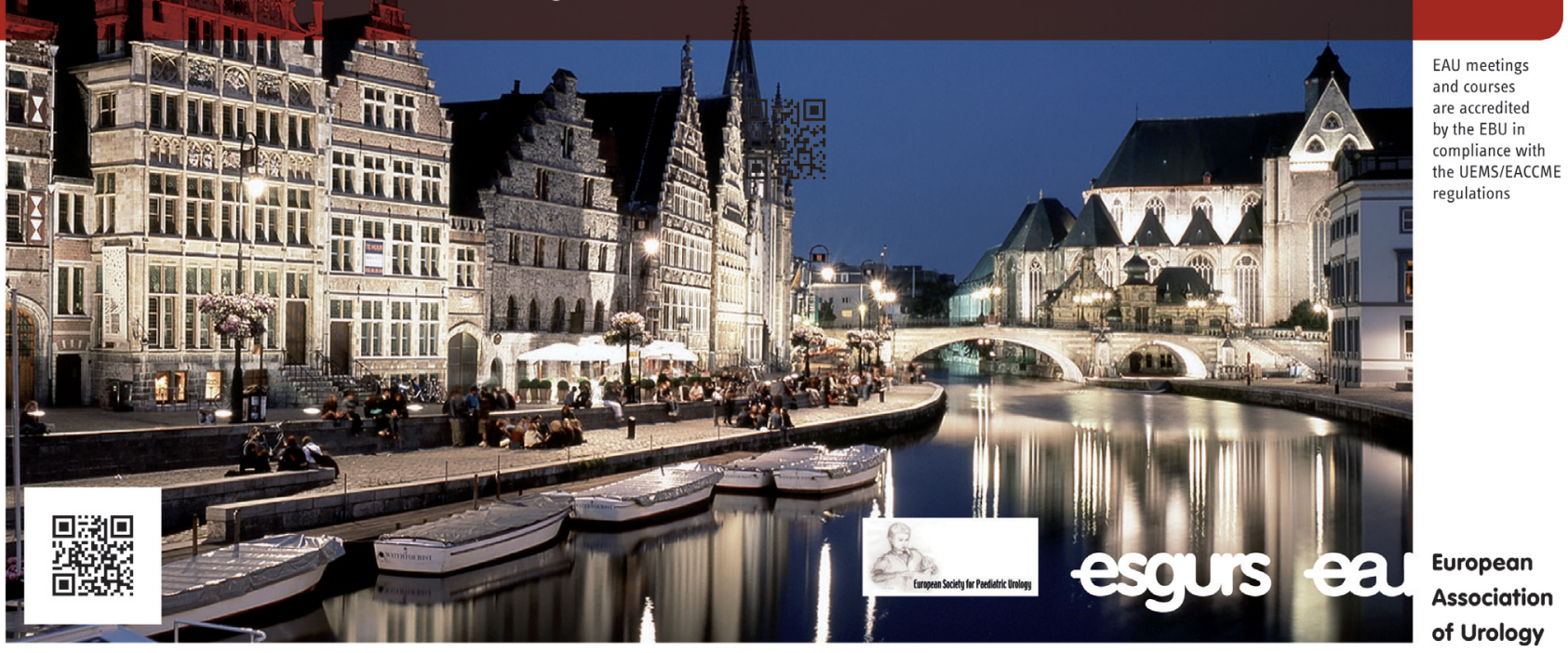

